\title{
An Author's Guide to Mastering Research Communication Skills: Introduction of a Medical Manuscript
}

\author{
Tamer A. El-Sobky \\ Division of Pediatric Orthopedics, Department of Orthopedic Surgery, Faculty of \\ Medicine, Ain Shams University, Cairo, Egypt, Email: tamer.ahmed@med.asu.edu.eg \\ ORCID iD: https://orcid.org/0000-0001-6510-9419
}

\begin{abstract}
Skilled academic/medical writing is critical to research communication. The fundamental sections of a scholarly manuscript are introduction, methods, results and discussion. The introduction of a medical manuscript is aimed at briefing readers on the clinical extent and public health context of the research problem. It must justify the essentialness of the research to the scientific community and reveal any underlying research novelty. Skillfully conceived, designed and performed research protocols that are unskillfully presented can lose scientific credibility and impact. Without research communication skills authors would not be able to display the usefulness of their research for the scientific community. Generally, research communication or medical writing training/skills is underrepresented in curricular systems of medical schools globally. This can challenge publication quality and quantity of early-career authors/researchers. The author presents the academic experience he accumulated through peer review and supervision of vast manuscripts and theses. This article aimed at presenting a comprehensive roadmap for academic writing of the introduction and at identifying its common pitfalls.
\end{abstract}

Keywords: medical writing, research communication, biomedical publications, teaching, medical education, article introduction, faculty training, early-career researchers, medical authorship 


\section{Introduction \& Background}

\section{Medical writing: An overlooked research dimension}

The introduction section of a scholarly manuscript is aimed at briefing the readers on the nature, clinical extent and public health context of the research problem. The introduction must justify the importance and essentialness of the research to the scientific community. It should also reveal any underlying novelty in the research problem. Noteworthy, skilfully conducted research that is unskillfully presented can lose credibility and scientific impact. There is evidence to suggest that research presentation/communication skills are underrepresented in curricular systems of medical schools globally [1-4]. This research communication gap can challenge publication quality and quantity especially of early-career authors. And it can limit the materialization and clinical usefulness of otherwise novel, insightful and well-executed research ideas. A significant amount of the current medical literature - systematic reviews- has a limited capacity to produce credible evidence and generalizable conclusions. This can be attributed to flawed original studies [5] or unjustified generalizations by authors of systematic reviews [6]. And is another indicator of inadequate research communication skills. Contrastingly, the global biomedical literature has enjoyed exponential growth lately http://www.scimagojr.com. According to the China Knowledge Resource Integrated Database, 499 doctoral degree-granting units' with 455000 doctoral dissertations, and 779 master degree-granting units' with 4 million master's theses, dating back to 1984 and cover multiple academic disciplines [7].

Publication pressures arising from university promotion, degrees and tenure commitments and intense career rivalry, the use of English as the language of instruction in medical schools and as the language of publication in most reputable biomedical journals and the rise of predatory publishing practices, that offer limited or no peer review, are all potential contributing factors to the inadequate research communication skills of early-career authors [8-10]. This is particularly applicable to non-native English-speaking authors from low and middle-income countries [4, 11, 12]. The above can put scholarly authors from non-English speaking countries at a disadvantage in terms of increased writing anxiety, increased journal rejection rates because of limited grammar proficiency and the economic burden of resorting to English language manuscript editing services [12-14]. The fact that a considerable percentage of preliminary research -conference abstracts- is not transformed into full-text publications may indicate that authors need to upgrade their research communication skills [15-17]. 
Consequently, practical initiatives have been taken to analyze the full scope of the problem and to improve academic writing and research communication skills of both undergraduate students and senior faculty members [18, 19]. These initiatives involved university-based [2, 3, 20-22], community-based [1, 4] and publisher-based [23] initiatives. Both academic reading and writing skills are equally essential to medical academics. Academic or research reading namely engaging in critical peer review of academic manuscripts is another important and overlooked tool to improve research writing/communication skills of early-career authors [24-26]. Unsurprisingly, authors and peer reviewers are equal co-partners, having critical and interchangeable roles in advancing medical sciences.

The above-noted observations have critical drawbacks to the medical literature, part of which is published in predatory journals, in terms of its quality and the potential for dissemination of inaccurate study inferences and conclusions into future research. The objective of this report was to present a comprehensive roadmap for "introduction" of a medical manuscript. The author articulated useful tips which may be used as a guide to the efficient communication of the introduction section (Figure 1).

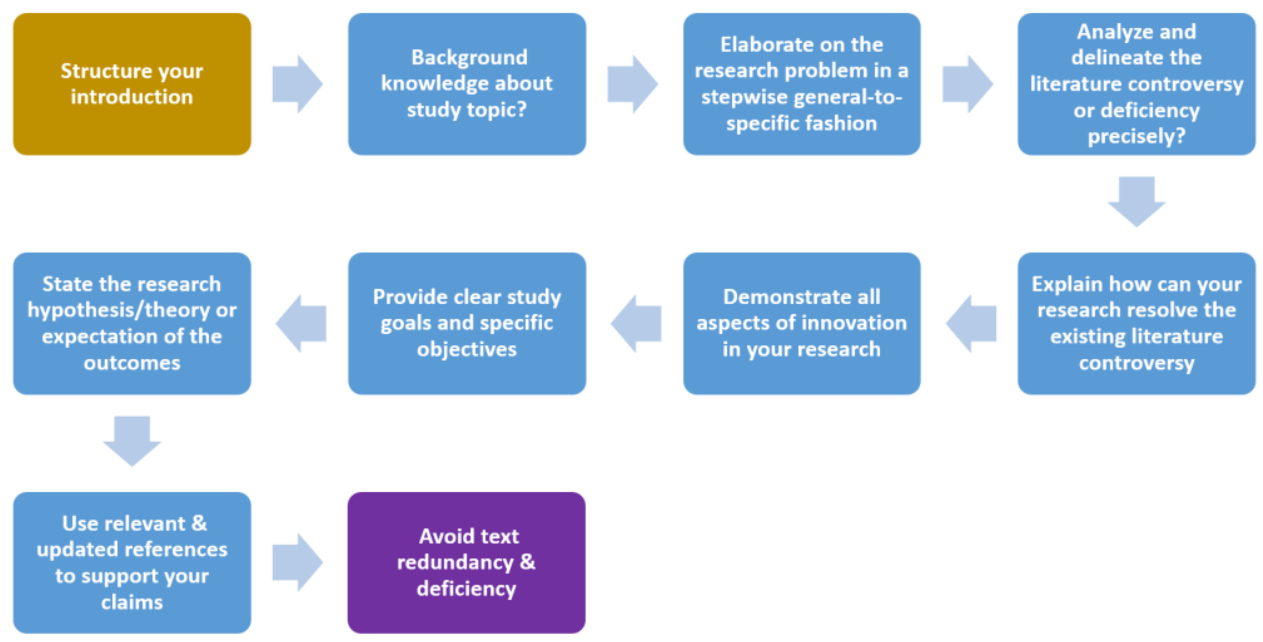

Figure 1: A roadmap to writing a purposeful introduction of a medical manuscript

\section{Review}

\section{Functions of the introduction}

The introduction section of a medical manuscript is the gateway to the importance and relevance of one's research work to the scientific community or the broader public health. A weakly constructed introduction may not encourage readers to continue reading the whole manuscript [27]. A purposeful introduction section of should clearly and concisely answer the following questions (Figure 2); 
1) What is the current background information pertinent to the specific research topic?

2) What is the lingering research problem or question that the scientific community is trying to answer?

3) Why is this research problem worthy of investigation? That is to say, are there any direct or indirect benefits to be derived from resolving this proposed research problem?

4) What strategies are the authors going to use to resolve this research problem?

5) What is the general goal and specific objectives of the research work?

Functions The Introduction Should Fulfill?

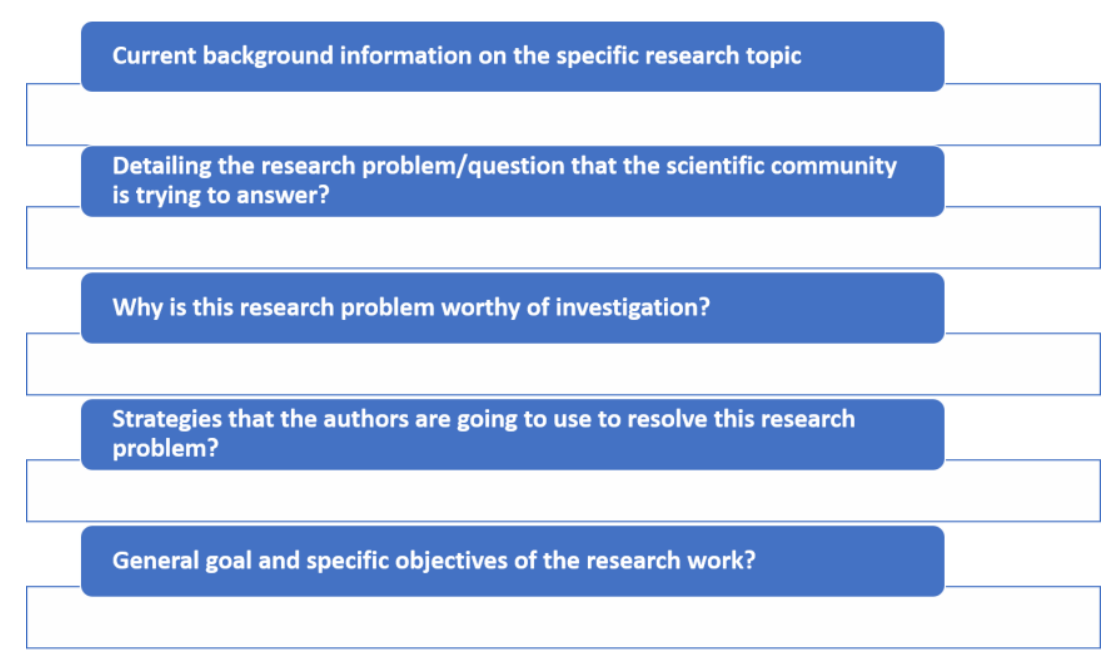

Figure 2: Functions of the introduction

\section{Structuring the introduction}

Before stating to write, structure the introduction. Structuring the introduction section of a medical manuscript helps the author articulate the scientific content and concepts in a logical flow pattern and makes it easier for readers to grasp the intended message from the introduction. Broadly speaking, the introduction may be structured into three functional and structural sub-sections namely a) providing sufficient background knowledge on the studied topic, b) explanation of the research problem and c) stating study general goals and specific objectives of the study, that is to say three main paragraphs. According to the nature of research or journal requirements, the introduction may need to be written in one paragraph. However, the previous proposed structure and logical flow of ideas still applies. 
Additionally, authors ought to acquire practical text summarizing and reduction skills. Summarizing skills entail the ability to select the most relevant text/information out of a larger amount, whereas reduction skills entail the ability to select a limited amount of text/information out of numerously similar/identical pieces of information [28]. Finally, authors are advised to exercise self-regulatory or self-monitoring skills of their own writing. In other words, it is the ability of the author to judge his own writing performance in view of the known standards -above- and bring about any necessary corrections [28]. Authors are advised to consult the instructions to authors section of the target journal in regard to word count.

\section{Providing background information}

Prior to embarking on the details of the research problem one should provide a general and concise piece of knowledge or background about the research domain or disorder to be studied. For example, an interventional study on cerebral palsy (CP) children should provide readers with the definition, incidence, most common subtypes and global public health implications of CP. Similarly, an interventional or descriptive study on a specific subtype or feature of genetic skeletal dysplasias should provide readers with a short paragraph on the definition and main features of genetic skeletal dysplasias in general [29]. Alternatively, studies that focus on a specific research methodology as survey research or randomized control trials in $\mathrm{CP}$ children can enlighten readers on the nature and scientific value of survey research in clinical practice irrespective of the enrolled study population. Beware, the potential readers of your manuscript may belong to multiple disciplines and have different levels of expertise in the manuscript's research topic.

\section{Approaching the research problem}

A logical flow of ideas or information includes a stepwise general-to-specific pattern and an old-to-recent pattern. When elaborating on the research problem follow a stepwise general-to-specific and an old-to-recent pattern. This aims to prepare the reader's minds to the most specific and focused research point that the study pivots around and addresses. Doing otherwise may undermine the importance of the research problem. For example, an interventional study that addresses the outcome of new or modified surgical technique for a certain pediatric orthopedic disorder should inform readers about the historical evolution of that technique. It should also highlight the main distinctions between each developmental phase of this surgical technique. Authors are not necessary required to mention and reference every particular technique. Rather, it is advised to break them down into categories where different surgical techniques that 
present a single stand-alone surgically meaningful entity can be categorized together e.g. soft tissue versus bony surgical techniques, multilevel versus single-level and multistage versus single-stage orthopedic surgery etc. [30]. Likewise, scoring systems or outcome measures in CP children have went through multiple developmental phases of objective physician-reported outcome measures until subjective patient-reported have dominated the scene namely health related quality-of-life measures.

Explaining to readers precisely where the controversy in the literature lies is critical to their engagement with the manuscript? Presenting a clear and appealing research problem necessitates a precise explanation of the literature controversy. Pointing out similarities or dissimilarities between various outcomes of literature studies is insufficient. Authors are required to inform readers/reviewers about the exact nature of these similarities or dissimilarities in study outcomes. Thus study outcomes' -similar or dissimilar- should be interpreted in view of various factors that may impact study evidence and lead to biased outcomes as; a) population characteristics e.g. small versus large sample size and homogenous versus heterogeneous sample, b) inappropriateness of the selected methodology for the study objectives e.g. an experimental case series with no control group versus a randomized control trial, c) diverse research designs e.g. prospective versus retrospective studies, d) methodological flaws as insufficient control of study's confounding variables e.g. high versus low surgeon volume/experience, e) diverse outcome measures e.g. validated versus invalidated measures and f) inherent study limitations as disease rarity or limited research resources (Figure 3).

\section{How to Approach The Research Problem or Question?}

Proceed in general-to-specific pattern to prepare thee
readers mind
Highlight the main distinctions between each
evolutionary phase of the research problem?
$\begin{gathered}\text { Explain clearly where does the literature controversy lie? } \\ \text { i.e. limitations and strengths of each viewpoint }\end{gathered}$
Explain clearly in what way will your research idea
resolve/lessen this controversy (research novelty)
Conclude by providing well-formulated study goals,
objectives and hypothesis

Figure 3: How to approach the research problem?

\section{Demonstrating novelty in research}


It is important to explain to readers how can your study resolve the literature controversy or compensate for the literature deficiency and produce innovation and evidence building. Innovation in research is important to the advancement in medicine. High-ranking journals always seek exclusivity in research ideas. However, innovation does not necessary mean a description a new surgical technique or an introduction of a new molecule or drug. This represents one aspect of research novelty only [30].

Various other aspects of research novelty are commonly overlooked. Methodologically proving that the bases behind a widely used surgical approach is unfounded is one form of research innovation e.g. the complete transition from extensive surgical correction to manipulative treatment in congenital club feet or the influence of clubfeet demographics on disease severity and prognosis [31]. A systematic review or meta-analysis of a debated and previously reported topic can produce new evidence, pinpoint methodological deficiencies in the literature and inspire future research [32, 33]. Construction and validation of a new or previously implemented scoring system as cross-cultural adaptation of an Arabic translated version of a CP assessment tool lends support to evidence-building in research [34]. Recalling patients of short term follow-up interventional studies with the purpose of assessment of their outcomes on the long term constitutes another form of non-surgical research innovation [35]. Overcoming the methodological deficiencies of a published research topic boosts research reliability and innovation. Providing the experimental bases for an unused surgical method in clinical practice is another example of innovative research that should be pointed out to readers and reviewers alike [36] (Figure 4).

\begin{tabular}{|c|c|}
\hline Demographics & $\begin{array}{l}\text { - Studying the effect of disease or patient demographics on disease severity or } \\
\text { responsiveness to treatment }\end{array}$ \\
\hline Evidence synthesis & $\begin{array}{l}\text { - Conducting a systematic review to build up new evidence on a certain research } \\
\text { problem }\end{array}$ \\
\hline Scoring system & - Validating or modifying an already implemented scoring system \\
\hline Register & $\begin{array}{l}\text { - Providing clinical and public health benefits by creating a pilot study for a } \\
\text { disease register }\end{array}$ \\
\hline Longer Follow up & $\begin{array}{l}\text { - Recalling patients of a short-term follow up study with the intention of recording } \\
\text { their long-term results }\end{array}$ \\
\hline Larger patient population & $\begin{array}{l}\text { - Studying the effectivity of a certain therapeutic/technique on the a larger } \\
\text { sample of the same patient population }\end{array}$ \\
\hline $\begin{array}{l}\text { Repeating } \\
\text { methodologically flawed }\end{array}$ & $\begin{array}{l}\text { - Repeating methodologically flawed studies after accommodating for the study } \\
\text { flaws }\end{array}$ \\
\hline studies & \\
\hline $\begin{array}{l}\text { New technique or patient } \\
\text { population }\end{array}$ & $\begin{array}{l}\text { - New technique or studying the effect of a published technique on a new patient } \\
\text { population }\end{array}$ \\
\hline
\end{tabular}

Figure 4: Examples of various aspects of research novelty 


\section{Formulating study objectives}

After concluding the extent and depth of the research problem, authors must provide a preliminary expectation of the final study outcomes. That is, the hypothesis upon which the study is based. Consequently, the introduction is usually concluded by writing unambiguous well-structured study objectives. This is because study objectives must align with the study methodology used to achieve these objectives and with final conclusions. A study may have a goal or primary objective which can be broken down into secondary objective(s). For example, a) the primary objective of this survey study was to examine the orthopedic surgeon's preferences and current practice to the evaluation and surgical management of equinus deformity in children with ambulatory $\mathrm{CP}, \mathrm{b})$ the secondary objective was to analyze variations in current practice between general orthopedic and pediatric orthopedic surgeons" [37]. In secondary research as systematic reviews it may be preferable to communicate one's objectives through research question(s) instead of direct statements [38]. A well-structured study objective must include the following components whenever applicable; a) intervention and outcomes e.g. to study the effect of constraint-induced movement therapy on activity and participation or the effect of bony hip reconstruction on health related quality-of-life measure, b) study population e.g. adolescents and young adults with spastic $\mathrm{CP}$ or young children with hemiplegic $\mathrm{CP}$ etc. c) follow up period e.g. short term versus long term, d) research type e.g. prospective versus retrospective, e) study methodology e.g. an observational analytical cohort study or an experimental non-randomized study with a normal control group. A roadmap to writing a purposeful introduction of a medical manuscript is shown. Remember that the study methodology and final conclusions would be weighed against the objectives provided by the authors in the introduction [39].

\section{Using references appropriately}

Relevant and updated references are essential to support the scientific declarations made in the introduction. References as review articles are needed to give broad or background information whereas more focused and research point-specific selected references are needed to address the particulars of the research problem.

Representative and relevant references are important to substantiate the information and viewpoints of the authors [40]. Irrelevant or inaccurate reference interpretations can undermine the credibility of the research problem. There are many grounds for inaccurate referencing practices e.g. a) irrelevance, discordance or contradictions between conclusions or interpretations made by the citing authors and those made by 
the cited reference, b) indirect referencing i.e. references that are not cited from the primary source, c) methodologically flawed references even if they are relevant to the authors' research point and d) references with obsolete information (surpassed by more recent and credible studies) even if methodologically robust [39, 40]. However, methodologically flawed and obsolete references may be used to showcase the limited evidence for the research point studied. Additionally, obsolete references/techniques may be used in a historical context. Authors must be beware of the consequences of citing predatory journals. The quality of manuscripts published in these predatory journals is highly questionable at best [8-10]. The sound referencing practices are summarized (Figure 5).

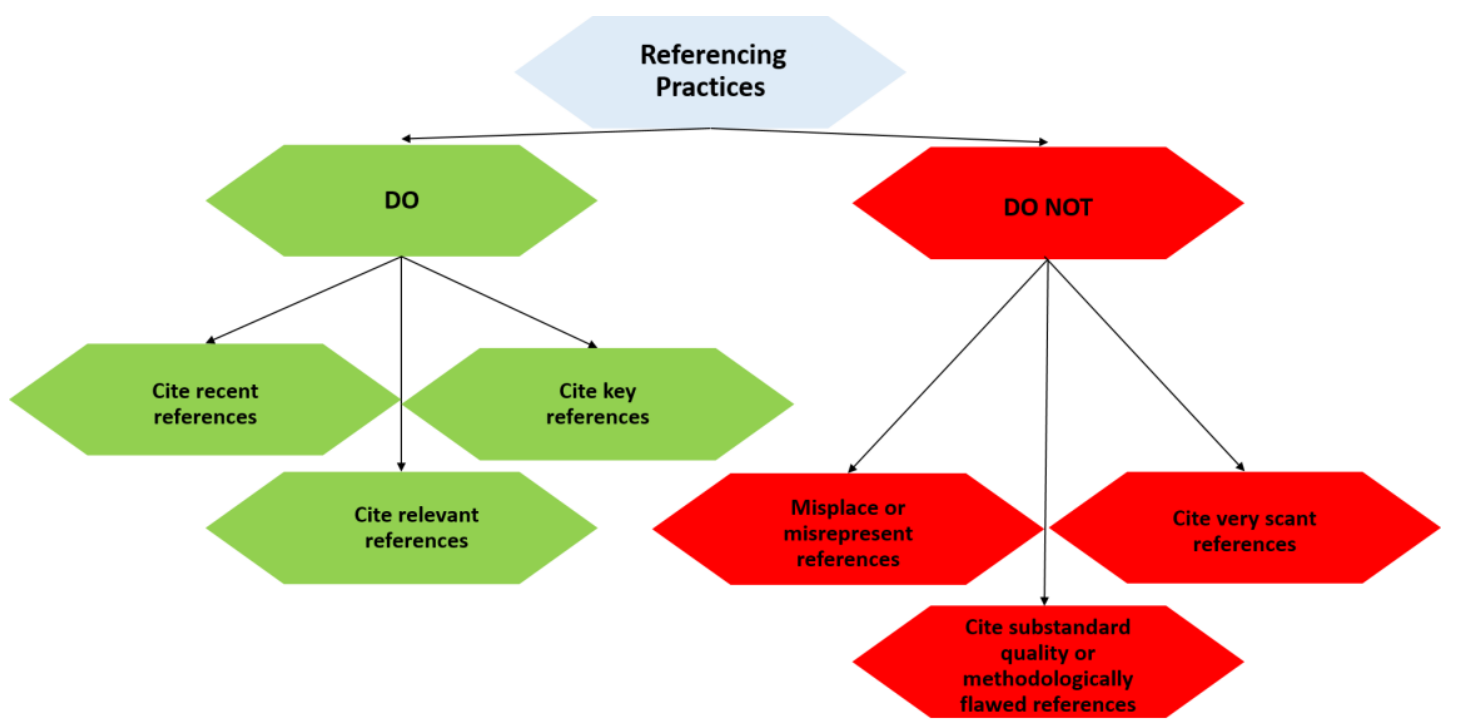

Figure 5: Sound referencing practices. Scant references: that do not allow for full elucidation of the research problem

An efficient introduction of a medical manuscript should strike an accurate balance between redundant (unnecessary) and deficient (oversimplified) information/text. Text redundancy may exhaust and eventually deter readers from reading until the end. Additionally, it may dilute or overshadow the core message the introduction aims to deliver. On the other hand, text deficiency may fail to explain the research problem properly. To maintain the correct balance between redundancy and deficiency, avoid irrelevant information, prioritize the essential points of the research problem and be equipped with good summarizing skills. The common pitfalls of writing an introduction of a medical manuscript are shown (Figure 6). Finally, continuous training and practice in academic writing has proved essential to the improvement of quality and quantity of research output. Peer support writing initiatives are demonstrable examples [20, 41, 42]. 


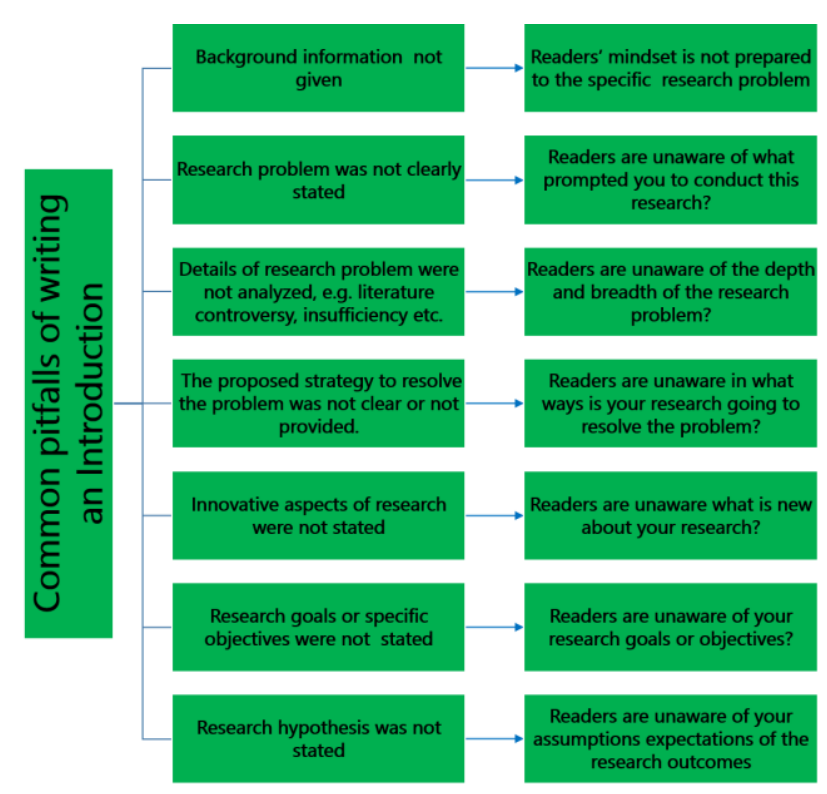

Figure 6: Common pitfalls of writing an introduction of a medical manuscript

\section{Conclusions}

Without adequate academic skills to present an intellect introduction, the true extent of the research problem and proposed study objectives may go largely undelivered to readers. Following a structured roadmap is essential to an efficient and scientificallymeaning introduction of biomedical manuscript. Academic skills required to conceptualize, design and implement research should go side by side with skills required to present and communicate research.

\section{Acknowledgements}

None

\section{Conflict of interest}

Nothing to declare

\section{Funding}

Nothing to declare

\section{References}

1. Oliveira LMA, Bonatelli ML, Pinto TCA: DivulgaMicro: A Brazilian initiative to empower early-career scientists with science communication skills. J Microbiol Biol Educ. 2019, 20:20.1.7. https://doi.org/10.1128/jmbe.v20i1.1616 
2. El Tantawi M, Sadaf S, AlHumaid J: Using gamification to develop academic writing skills in dental undergraduate students. Eur J Dent Educ. 2018, 22:1522. https://doi.org/10.1111/eje.12238

3. Sahoo S, Mohammed CA: Fostering critical thinking and collaborative learning skills among medical students through a research protocol writing activity in the curriculum. Korean J Med Educ. 2018, 30:109-18. https://doi.org/10.3946/kjme.2018.86

4. Sabouni A, Chaar A, Bdaiwi Y, et al.: An online academic writing and publishing skills course: Help Syrians find their voice. Avicenna J Med. 2017, 7:103-9. https://doi.org/10.4103/ajm.AJM 20416

5. Valdez D, Vorland CJ, Brown AW, et al.: Improving open and rigorous science: ten key future research opportunities related to rigor, reproducibility, and transparency in scientific research. F1000Res. 2020, 9:1235. https://doi.org/10.12688/f1000research.26594.1

6. McGrath TA, McInnes MDF, van Es N, Leeflang MMG, Korevaar DA, Bossuyt PMM: Overinterpretation of research findings: evidence of "spin" in systematic reviews of diagnostic accuracy studies. Clin Chem. 2017, 63:135362. https://doi.org/10.1373/clinchem.2017.271544

7. oversea.cnki.net [Internet]. China Knowledge Resource Integrated Database: Theses and Dissertations Database; c2021 [cited 2021 May 31]. Available from: https://oversea.cnki.net/index/

8. Sener M, Davulcu CD, Tahta M, Gunal I: Predatory journal preference in the field of orthopaedics and traumatology in Turkey. Acta Orthop Traumatol Turc. 2019, 53:390-3. https://doi.org/10.1016/j.aott.2019.05.003

9. Yan JR, Baldawi H, Lex JR, Simchovich G, Baisi LP, Bozzo A, Ghert M: Predatory publishing in orthopaedic research. J Bone Joint Surg Am. 2018, 100:e138. https://doi.org/10.2106/JBJS.17.01569

10. Gasparyan AY, Nurmashev B, Voronov AA, Gerasimov AN, Koroleva AM, Kitas GD: The pressure to publish more and the scope of predatory publishing $\begin{array}{lllll}\text { activities. J Korean } & \text { Med }\end{array}$ https://doi.org/10.3346/jkms.2016.31.12.1874

11. Schimanski LA, Alperin JP: The evaluation of scholarship in academic promotion and tenure processes: Past, present, and future. F1000Res. 2018, 7:1605. https://doi.org/10.12688/f1000research.16493.1

12. Duracinsky M, Lalanne C, Rous L, et al.: Barriers to publishing in biomedical journals perceived by a sample of French researchers: results of the 
DIAzePAM study. BMC Med Res Methodol. 2017, 17:96. https://doi.org/10.1186/s12874-017-0371-z

13. Zhang CJ, Zhu Y: China's graduate students need better education in scientific writing and publishing. J Zhejiang Univ Sci B. 2016, 17:409-12. https://doi.org/10.1631/jzus.B1600174

14. Ramírez-Castañeda V: Disadvantages in preparing and publishing scientific papers caused by the dominance of the English language in science: The case of Colombian researchers in biological sciences. PLoS One. 2020, 15:e0238372. https://doi.org/10.1371/journal.pone.0238372

15. Grover S, Dalton N: Abstract to publication rate: Do all the papers presented in conferences see the light of being a full publication?. Indian J Psychiatry. 2020, 62:73-9. https://doi.org/10.4103/psychiatry.IndianJPsychiatry 32019

16. Yalçınkaya M, Bagatur E: Fate of abstracts presented at a national Turkish orthopedics and traumatology congress: publication rates and consistency of abstracts compared with their subsequent full-text publications. Acta Orthop Traumatol Turc. 2013, 47:223-30. https://doi.org/10.3944/aott.2013.3073

17. Alrashidi YA, Alrabai HM: Barriers to conduction or completion of research projects among orthopedic surgeons in Saudi Arabia. J Musculoskelet Surg Res 2021,5:103-8. https://doi.org/10.4103/jmsr.jmsr 421

18. Haven TL, Bouter LM, Smulders YM, Tijdink JK: Perceived publication pressure in Amsterdam: Survey of all disciplinary fields and academic ranks. PLoS One. 2019, 14:e0217931. https://doi.org/10.1371/journal.pone.0217931

19. Oppenheimer D, Zaromb F, Pomerantz JR, Williams JC, Park YS: Improvement of writing skills during college: A multi-year cross-sectional and longitudinal study of undergraduate writing performance. Assessing Writing. 2017, 32:1227. https://doi.org/10.1016/j.asw.2016.11.001

20. Wortman-Wunder E, Wefes I: Scientific writing workshop improves confidence in critical writing skills among trainees in the biomedical sciences. J Microbiol Biol Educ. 2020, 21:21.1.5. https://doi.org/10.1128/jmbe.v21i1.1843

21. Franks AM: Design and evaluation of a longitudinal faculty development program to advance scholarly writing among pharmacy practice faculty. Am J Pharm Educ. 2018, 82:6556. https://doi.org/10.5688/ajpe6556

22. Gayle AA, Shimaoka M: Evaluating the lexico-grammatical differences in the writing of native and non-native speakers of English in peer-reviewed medical journals in the field of pediatric oncology: Creation of the genuine index scoring system. PLoS One. 2017, 12:e0172338. https://doi.org/10.1371/journal.pone.0172338 
23. researcheracademy.elsevier.com [Internet]. Elsevier: Researcher Academy; c2021 [cited 2021 May 30]. Available from: https://researcheracademy.elsevier.com/

24. McNair R, Phuong HAL, Cseri L, Szekely G: "Peer review of manuscripts: a valuable yet neglected educational tool for early-career researchers," Education Research International. vol. 2019, Article ID 1359362, 9 pages, 2019. https://doi.org/10.1155/2019/1359362

25. Hubbard KE, Dunbar SD: Perceptions of scientific research literature and strategies for reading papers depend on academic career stage. PLoS One. 2017, 12:e0189753. https://doi.org/10.1371/journal.pone.0189753

26. Kulage KM, Larson EL: Implementation and outcomes of a faculty-based, peer review manuscript writing workshop. J Prof Nurs. 2016, 32:262-70. https://doi.org/10.1016/j.profnurs.2016.01.008

27. Bahadoran Z, Jeddi S, Mirmiran P, Ghasemi A: The principles of biomedical scientific writing: Introduction. Int J Endocrinol Metab. 2018. 16:e84795. https://doi.org/10.5812/ijem.84795

28. Wischgoll A: Combined training of one cognitive and one metacognitive strategy improves academic writing skills. Front Psychol. 2016, 7:187. https://doi.org/10.3389/fpsyg.2016.00187

29. El-Sobky TA, Shawky RM, Sakr HM, Elsayed SM, Elsayed NS, Ragheb SG, Gamal R: A systematized approach to radiographic assessment of commonly seen genetic bone diseases in children: A pictorial review. J Musculoskelet Surg Res. 2017, 1:25-32. https://doi.org/10.4103/jmsr.jmsr 2817

30. Baraka MM, Hefny HM, Mahran MA, Fayyad TA, Abdelazim H, Nabil A: Singlestage medial plateau elevation and metaphyseal osteotomies in advancedstage Blount's disease: a new technique. J Child Orthop. 2021, 15:12-23. https://doi.org/10.1302/1863-2548.15.200157

31. Salvatori G, Bettuzzi C, Abati CN, Cucca G, Zanardi A, Lampasi M: The influence of laterality, sex and family history on clubfoot severity. J Child Orthop. 2020, 14:145-150. https://doi.org/10.1302/1863-2548.14.190184

32. Fahr A, Keller JW, van Hedel HJA: A Systematic review of training methods that may improve selective voluntary motor control in children with spastic cerebral palsy. Front Neurol. 2020, 11:572038. https://doi.org/10.3389/fneur.2020.572038

33. Abd El-Nabie WA, Abd El Aziz H, Elshennawy S: Effect of walking aids and foot orthoses on energy expenditure in children with cerebral palsy: a systematic review. Bull Fac Phys Ther. 2019, 24:99-112. https://doi.org/10.4103/bfpt.bfpt 319 
34. Alnahdi AH, Alhusaini AA, Yousef B, Alshami A: The Arabic version of the ABILOCO-Kids scale is valid and reliable in children with cerebral palsy. Physiother Theory Pract. 2020, 1-9. https://doi.org/10.1080/09593985.2020.1736222

35. Dreher T, Thomason P, Švehlík M, et al.: Long-term development of gait after multilevel surgery in children with cerebral palsy: a multicentre cohort study. Dev Med Child Neurol. 2018, 60:88-93. https://doi.org/10.1111/dmcn.13618

36. Cobanoglu M, Cullu E, Kilimci FS, Ocal MK, Yaygingul R: Rotational deformities of the long bones can be corrected with rotationally guided growth during the growth phase. Acta Orthop. 2016, 87:301-5. https://doi.org/10.3109/17453674.2016.1152450

37. Gendy S, ElGebeily M, El-Sobky TA, Khoshhal KI, Jawadi AH: Current practice and preferences to management of equinus in children with ambulatory cerebral palsy: A survey of orthopedic surgeons. SICOT J. 2019; 5:3. https://doi.org/10.1051/sicotj/2019003

38. Milne N, Miao M, Beattie E: The effects of serial casting on lower limb function for children with cerebral palsy: a systematic review with metaanalysis. BMC Pediatr. 2020; 20:324. https://doi.org/10.1186/s12887-020-02122$\underline{9}$

39. El-Sobky TA: An author's guide to mastering academic writing skills: Discussion of a medical manuscript. J Musculoskelet Surg Res. 2021; 5:227-34. https://doi.org/10.25259/JMSR 792021

40. Pavlovic V, Weissgerber T, Stanisavljevic D, et al.: How accurate are citations of frequently cited papers in biomedical literature? Clin Sci (Lond). 2021; 135:671-681. https://doi.org/10.1042/CS20201573

41. Manzano-Nunez R, Ariza F, Rengifo JE, Munoz LE, Gempeler A, Ortega G, García AF: A Scoping review of peer support writing groups in academic medicine as a valuable tool for physician-scientists in the publish or perish era. Med Sci Educ. 2020, 30:1313-1319. https://doi.org/10.1007/s40670-02000983-4

42. Brandon C, Jamadar D, Girish G, Dong Q, Morag Y, Mullan P: Peer support of a faculty "writers' circle" increases confidence and productivity in generating scholarship. Acad Radiol. 2015, 22:534-8. https://doi.org/10.1016/j.acra.2014.12.006 


\section{Figure Legends}

- Figure 1: A roadmap to writing a purposeful introduction of a medical manuscript

- Figure 2: Functions of the introduction

- Figure 3: How to approach the research problem?

- Figure 4: Examples of various aspects of research novelty

- Figure 5: Sound referencing practices. Scant references: that do not allow for full elucidation of the research problem.

- Figure 6: Common pitfalls of writing an introduction of a medical manuscript 